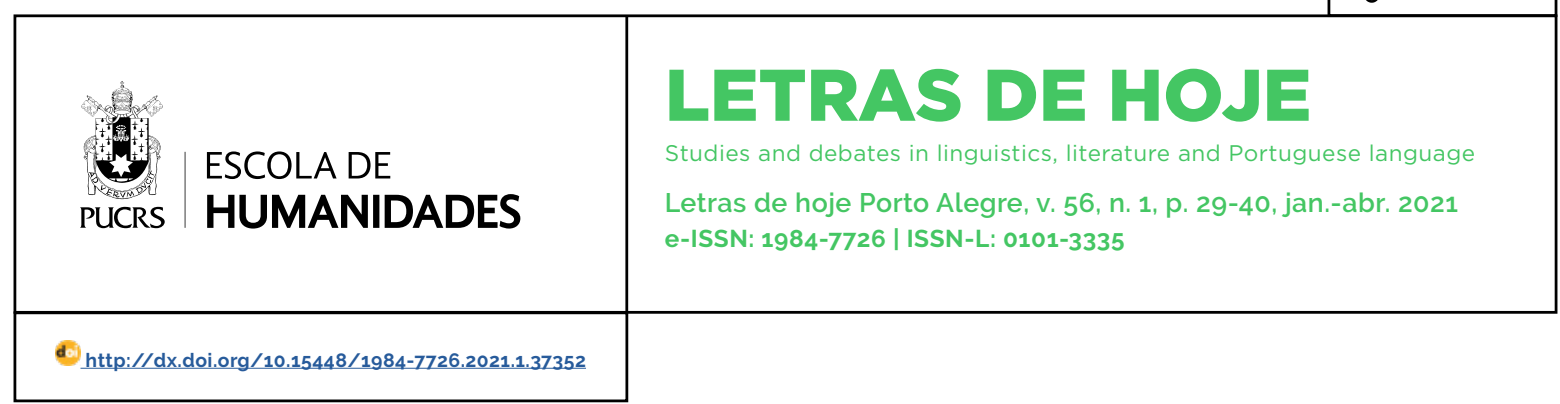

SEÇÃO: TEMÁTICA LIVRE

\title{
Juó Bananére, um escritor íntalo-brasiliano
}

\author{
Juó Bananére, an Italian Brazilian writer \\ Juó Bananére, un escritor intalo-brasiliano
}

\section{Benedito Antunes ${ }^{1}$}

orcid.org/0000-0001-8269-4410

benedito.antunes@unesp.br

Recebido em: 14 mar. 2020.

Aprovado em: $21 \mathrm{fev} .2021$.

Publicado em: 11 jun. 2021.

\section{(c) (1)}

Artigo está licenciado sob forma de uma licença Creative Commons Atribuição 4.0 Internacional.
Resumo: Este artigo tem como finalidade analisar a linguagem de Juó Bananére, pseudônimo de Alexandre Ribeiro Marcondes Machado (1892-1933), procurando compreender suas implicações literárias e históricas no contexto brasileiro do início do século XX. Baseando-se no linguajar do imigrante italiano, que misturava o português com o italiano, o autor criou a representação cômica desse imigrante. que enfrenta dificuldades para se inserir na sociedade brasileira. Destaca-se nessa figura o estilo macarrônico por meio do qual foram abordados diversos temas de ordem social, política, histórica e cultural, em especial a literária. Propõe-se aqui examinar especificamente a face de escritor dessa personagem, que se declarava poeta, barbeiro e jornalista, a fim de se observar de que maneira ela representa, mais do que a situação do imigrante italiano, a condição do Brasil como país colonizado que vive as contradições resultantes desse processo. A abordagem da figura de Juó Bananére dialoga com estudos específicos sobre o autor, enquanto as questões relacionadas à condição colonial brasileira inspiram-se em sugestões de Sérgio Buarque de Holanda.

Palavras-chave: Estilo macarrônico. Juó Bananére. Modernismo brasileiro. Literatura e história.

Abstract: This paper was carried out to analyze the language of Juó Bananére, pseudonym used by Alexandre Ribeiro Marcondes Machado (1892-1933), trying to understand his literary and historical implications within Brazilian context at the beginning of the $20^{\text {th }}$ century. Based on the Italian immigrant's jargon which mixed Portuguese with Italian, the writer created a comic representation of that immigrant, who faced difficulties in order to adapt himself to Brazilian society. In that creation one points out the broken style through which several issues concerning the social, political, historical and cultural order were broached, notably the literary one. One proposes here to analyze specifically Juó Bananére's writer face, who said he was himself a poet, barber and journalist, in order to observe the way the character represents, more than the Italian immigrant's situation, the status of Brazil as a colonized country facing the contradictions resulted from such a process.

Keywords: Broken style. Juó Bananére. Brazilian modernism. Literature and history.

Resumen: Este artigo tiene el objetivo de analizar el lenguaje de Juó Bananére, seudónimo del escritor brasileño Alexandre Ribeiro Marcondes Machado (18921933), tratando de comprender sus implicaciones literarias e históricas en el contexto brasileño de principios del siglo XX. Tomando como base la forma de hablar del inmigrante italiano en Brasil, que mezclaba el portugués con el italiano, el escritor creó una representación cómica de dicho inmigrante, que enfrenta dificultades para integrarse en la sociedad brasileña. Llama la atención en dicha figura el estilo macarrónico por intermedio del cual se trataron diversos temas de orden social, político, histórico, cultural y, en especial, literarios. Se propone aqui a examinar la faceta de escritor de dicho personaje, que se declara poeta, barbero y periodista, a fin de observar de qué modo representa, más que la situación del inmigrante italiano, la situación de Brasil como país colonizado que sufre las contradicciones resultantes de ese proceso. El abordaje de la figura de Juó Bananére dialoga con estudios especificos sobre el autor, mientras las 
cuestiones asociadas a la condición colonial brasileña se inspiran en el pensamiento de Sérgio Buarque de Holanda (1902-1982), reconocido pensador brasileño.

Palablas clave: Estilo macarrónico. Juó Bananére. Modernismo brasileño. Literatura e historia.

\section{Introdução}

A deformação linguística contida no título deste ensaio objetiva sugerir, num plano mais evidente, uma caracterização do próprio Juó Bananére, uma figura ambígua, que ora remete ao seu criador, Alexandre Ribeiro Marcondes Machado (1892-1933), funcionando como uma espécie de pseudônimo, ora se constitui como personagem que circulou em periódicos e jornais das primeiras décadas do século XX, fazendo crítica humorística a vários aspectos da sociedade brasileira. Num segundo plano, há uma questão de complexidade maior, que permeia o processo de formação e de evolução da vida cultural e literária brasileira e, sob certos aspectos, pode ser representada pelo escritor Juó Bananére.

Sem desprezar o processo de caracterização de Bananére, é o segundo plano que interessa como objeto central desta abordagem. Pretende-se, em linhas gerais, traçar o perfil de um suposto escritor ítalo-brasileiro, em que a plausibilidade contida no termo condicional aponta para a sua natureza paródica. A título de hipótese, pode-se considerar que um típico escritor brasileiro de origem italiana, ou por ter nascido na Itália, ou por ter herdado traços significativos de sua cultura, é aquele que vive no Brasil e escreve em português, ou mesmo em italiano, procurando tematizar questões inerentes à sua condição. Nesse caso, o tratamento dado à matéria, sério ou cômico, por exemplo, não alteraria sua condição italo-brasileira. No caso de Bananére, a particularidade reside na escolha linguística do escritor, que, em vez de optar por uma ou outra língua, adota a mistura das duas, numa imitação cômica daquilo que se verificava no meio social, em que uma grande quantidade de italianos recém-imigrados para São Paulo praticava um arremedo das duas línguas. Dentre as inúmeras implicações dessa opção, será abordada aqui a própria figura do escritor que surge nesse processo.
Observa-se, por esse ângulo, que se está diante da situação ambígua mencionada no início, uma vez que se sobrepõe ao possivel escritor macarrônico a figura de um escritor fictício, criada pelo próprio Bananére. Trata-se de um processo paródico, em que um autor, em vez de se inserir num sistema literário para produzir seus textos, criando para isso as configurações usuais de autores implícitos, instaura um universo ficcional em que ele próprio se apresenta como escritor. Deixa de ser, portanto, um escritor no primeiro plano para se tornar uma espécie de desdobramento em segundo plano, isto é, uma paródia dentro da paródia, o que amplia significativamente a dimensão macarrônica dos textos. A imitação elementar da língua falada pelos imigrantes italianos, que pode ser mais propriamente designada como língua macarrônica, evolui, assim, para um estilo macarrônico, em que as imitações se multiplicam e dão sustentação à própria figura de um escritor. Dessa forma, a aproximação da língua italiana à portuguesa por meio do estilo macarrônico cria uma perspectiva original para a representação das questões sociais e históricas brasileiras que transcendem a situação do imigrante.

\section{Contextualização de Juó Bananére}

Juó Bananére é o pseudônimo, ou a persona, ou o heterônimo, ou, para se fazer justiça ao sucesso do nome, a personagem pela qual ficou conhecido o engenheiro Alexandre Ribeiro Marcondes Machado. Como se pode perceber pelo nome, ele não tem nada de italiano. Nasceu em Pindamonhangaba, no interior de São Paulo, em 1892, e morreu na capital do Estado, em 1933, aos 41 anos de idade. Dizem que sua proximidade com os imigrantes italianos se deve à frequência ao curso de engenharia civil na Escola Politécnica de São Paulo, situada na rua Três Rios, no Bom Retiro. Isso lhe teria permitido conviver intensamente com o vozeio do bairro, uma mistura de português e italiano, geralmente nas variantes populares e dialetais (DERTÔNIO, 1975). A explicação faz sentido, mas talvez seja insuficiente, pois não era difícil conviver com italianos na São Paulo do início do século XX 
em virtude da grande quantidade de imigrantes.

Uma das poucas imagens que se conhece de Alexandre Machado é um aparente retrato em 3×4 de documento de identidade (Figura 1).

Figura 1 - Retrato de Alexandre Ribeiro Marcondes Machado

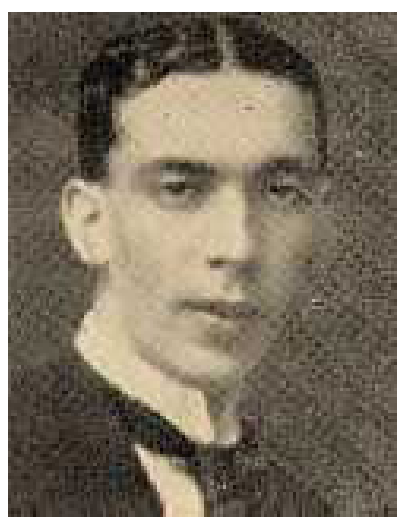

Fonte: Biblioteca Central Irmão José Otão, PUCRS. ${ }^{2}$

No âmbito pessoal, são conhecidos também alguns edifícios projetados pelo engenheiro ou por seu escritório, como o Hotel Municipal e a Casa da Cultura de Araraquara, estado de São Paulo, ambos em estilo neocolonial. Aliás, a sua única publicação em português é um livro sobre a arquitetura neocolonial. No mais, ele foi Juó Bananére.

Antes, porém, de tratar da figura do escritor, convém apresentar, ainda que breve e esquematicamente, o contexto em que ele surgiu e se tornou famoso. Essa apresentação é necessária porque Juó Bananére, apesar de ter sido muito conhecido em sua época, não é, a rigor, reconhecido como escritor. As histórias da literatura brasileira sequer mencionam a sua produção, e quando o fazem consideram-na principalmente como textos humorísticos, sem valor estético. Com efeito, os seus escritos passam ao largo da literatura consagrada, pois se caracterizam pela sátira dos fatos sociais, políticos e históricos e, claro, pela paródia de aspectos culturais de um modo geral, em particular da própria literatura.

Para situar Bananére no contexto literário brasileiro, é preciso considerar o peso do Modernismo, principalmente a chamada "fase heroica". Da perspectiva da vanguarda modernista, depois de Machado de Assis não teria havido nenhuma produção literária significativa até o surgimento dos modernistas, tanto que a historiografia costuma referir-se à literatura do periodo como "literatura de permanência" (CANDIDO, 1973, p. 113. grifo do autor).

O termo "Pré-modernismo", que vem sendo utilizado para designar essa fase, reflete de algum modo essa avaliação. Criado por Alceu Amoroso Lima, ele foi consagrado por Alfredo Bosi, que o separa em duas acepções: uma cronológica, que englobaria tudo o que se produziu antes do Modernismo; outra estética, que se restringe aos autores que anteciparam traços do Modernismo (a exemplo da visão crítica da sociedade brasileira, em contraposição à literatura mais conservadora). Nesta segunda acepção, seriam pré-modernistas um Lima Barreto, um Monteiro Lobato, um Euclides da Cunha (BOSI, 1969).

Mais recentemente, tem-se procurado estudar o período com outros critérios, tendência que coincide com o amadurecimento da crítica sobre o próprio Modernismo. Hoje, depois de esse movimento ter sido amplamente reconhecido e estudado, já é possível apontar o aspecto um tanto datado que recobre, por exemplo, a prosa de Memórias sentimentais de João Miramar, de Oswald de Andrade, sem que se venha a ser acusado de reacionário por algum vanguardista cioso de seus precursores.

José Paulo Paes (1985), no ensaio "O art nouveau na literatura brasileira", lança a hipótese de que o estilo predominante desse periodo literário teria sido o art nouveau, uma manifestação estética caracterizada pelo ornamental e pelo exuberante, nos moldes da Belle Époque. O crítico distingue, porém, a ornamentação superficial de um João do Rio ou de um Coelho Netto, da ornamentação essencial de um Euclides da Cunha e mesmo de um Monteiro Lobato, em que a adjetivação e as intercalações explicativas se combinam com o projeto temático da obra, como se pode verificar em Os sertões, de Euclides da Cunha.

Tudo indica que a proposta não vingou, mas o mérito do ensaísta consistiu em criar uma nova perspectiva para se observar o periodo, permitindo que se pergunte, por exemplo, se toda a 
produção que antecede o Modernismo configurava realmente estagnação cultural e literária. Até porque o Modernismo não nasce do nada. Como se sabe, a historiografia, ao eleger o seu cânone, trabalha com os picos, cuja escolha está sujeita a valores e a influências ideológicas. E não se pode esquecer que a atuação dos modernistas e dos que reabilitaram o movimento a partir dos anos de 1960, como ocorre em todas as vanguardas, teve sempre um papel preponderante no processo de escolha e valorização desse cânone.

Assim, torna-se conveniente reexaminar o período, deixando em suspensão a eventual cristalização de autores, obras e gêneros literários. Com efeito, a expansão dos estudos literários, dentro e fora das universidades, tem proporcionado atualmente uma situação propicia para revisões de diversa ordem. Isso tem permitido releituras de Hilário Tácito, Simões Lopes Neto, do próprio João do Rio e até de Lima Barreto, Euclides da Cunha, entre muitos outros. Também tem estimulado a redescoberta de autores quase desaparecidos nos diversos periódicos literários e humorísticos publicados no início do século XX. É esse novo olhar que está ensejando também a redescoberta ou a reavaliação de Juó Bananére, que tem sido objeto de diversos estudos nas áreas de Literatura, História e Cultura, além de fonte para documentários, recitais e espetáculos teatrais. ${ }^{3}$

\section{A construção de um escritor}

Alexandre Ribeiro Marcondes Machado criou Juó Bananére quando deu uma linguagem verbal a uma das mais famosas caricaturas de Voltolino, pseudônimo de Lemmo Lemmi (1884-1926), famoso por ter imortalizado diversos tipos italianos de São Paulo (BELLUZZO, 1992). Esse processo ocorreu no semanário paulistano O Pirralho, fundado por Oswald de Andrade em 1911 e publicado até 1917. A figura de Juó Bananére começou a se corresponder com a de Annibale Scipione - uma criação de Oswald de Andrade -, que assinava a coluna As Cartas d'Abax'o Pigues. Scipione, tam- bém em traço de Voltolino, lembra o imigrante em ascensão: apesar dos bigodes em pontas, ostenta elegante casaca e tem pose de gente bem-sucedida (Figura 2).

Figura 2 - Desenho de Annibale Scipione

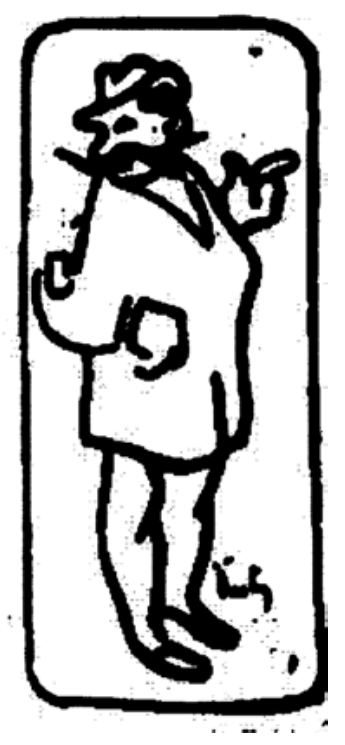

Fonte: O Pirralho, São Paulo, n. 2, p. 7, 19 ago. 1911.

Tendo de se ausentar do Brasil, Oswald de Andrade convida o estudante Alexandre Machado, então com 19 anos, para substitui-lo. Ele aparece, como Juó Bananére, no número 10 da revista, ao lado de Scipione, e a partir do número 11 continua sozinho na coluna (Figura 3). A sua figura apresenta traços mais populares e cômicos do que a de seu antecessor, tanto na cabeleira desgrenhada, nos bigodões em pontas e nas pernas arqueadas, como na casaca, no chapéu, na impagável bengala e no cachimbo fumarento que o acompanham. Com isso, a figura de Bananére passaria a evocar os imigrantes italianos mais populares, simbolizados por aqueles que viviam na Baixada do Piques, um bairro pobre e densamente povoado por operários italianos que se localizava mais ou menos onde é hoje a Praça da Bandeira.

Figura 3 - Desenho de Juó Bananére 


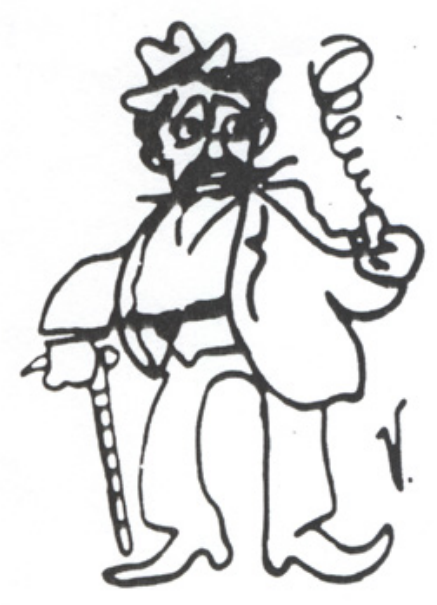

Fonte: O Pirralho, n. 10, p. 9, 14 out. 1911.

Essas representações não eram imotivadas. Numa cidade como a São Paulo da época, povoada de imigrantes de diversas nacionalidades, era comum surgirem imitações cômicas do seu modo de falar, alimentadas geralmente por certo sentimento de recusa ao estrangeiro que ocupava a cidade. No próprio Pirralho havia, além de Bananére, outras figuras cômicas que imitavam o francês, o alemão e até a variante caipira do português. $O$ imigrante italiano, enquanto habitante majoritário da cidade, foi talvez o objeto mais frequente de diversas manifestações culturais na música, no teatro, na literatura, em revistas cômicas, quase sempre na forma de maliciosas caricaturas.

E pode ser que Oswald de Andrade, ao criar a coluna no semanário, não tenha ido muito além de uma intenção humorística semelhante à exploração mais corrente da situação do imigrante, que consistia em imitar o linguajar ouvido nos bairros populares do Brás, Bixiga, Bom Retiro, Barra Funda, Piques. Já Alexandre Machado acabou assumindo perspectiva um pouco diferente, fazendo que a figura de Bananére mantenha seu interesse ainda hoje. Provavelmente porque logrou ir além dessa imitação um tanto preconceituosa do linguajar dos forasteiros, atingindo um nivel de criação textual que the permitiu evoluir para um estilo literário. De certa forma, ao superar o macarrônico enquanto incapacidade de falar bem determinada língua, o autor deslocou esse linguajar para uma espécie de nivel superior, que poderia ser designado por gênero macarrônico.
Diversos fatores contribuiram, portanto, para a caracterização de Juó Bananére. Inicialmente, há a caricatura de Voltolino, criada antes de Alexandre Machado adotá-la como expressão de sua personagem. Segundo Ana Maria Belluzzo, das personagens criadas por Voltolino, Bananére foi a "mais aceita e retomada por outros artistas", que the davam "novos tratamentos" (1992, p. 161). Assim, Alexandre Machado teria encontrado já prontos o pseudônimo e a caricatura da figura que se sobreporia à sua própria personalidade. Mas Juó Bananére tomará vida essencialmente pela linguagem desenvolvida por seu criador. Em sintese, pode-se dizer que Juó Bananére é produto de duas caricaturas que se combinam: de um lado, a imagem cômica do imigrante italiano na pena de Voltolino; de outro lado, a imitação do linguajar desse imigrante. Seu criador levou o projeto tão a sério que deixou a voz de Bananére registrada em discos, nos quais lê as suas histórias e canta paródias musicais. O próprio Voltolino tratou de acompanhar a evolução da personagem, incorporando novos traços à representação da figura do escritor. Na edição de 4 de setembro de 1915 de O Pirralho, ao lado dos poemas "O Gazua i a Polizia" e "Sunetto crassico", surge, assim, uma das mais completas e sugestivas imagens do escritor (Figura 4).

Figura 4 - Desenho de Juó Bananére

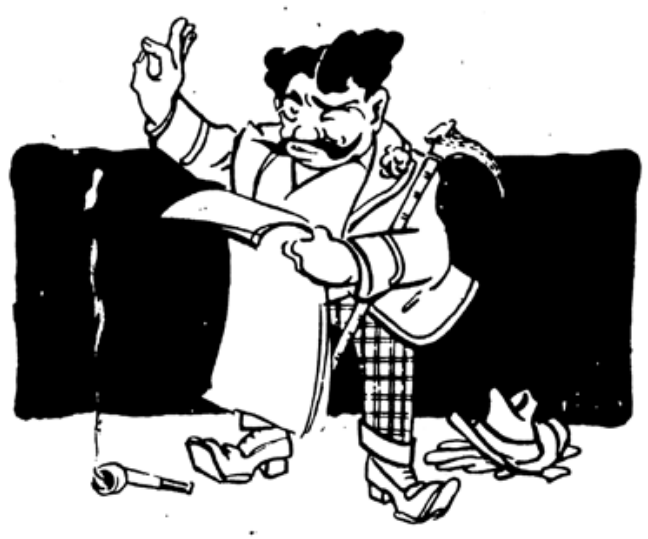

Fonte: O Pirralho, ano 5, n. 201, p. 42, 4 set. 1915.

A figura é praticamente a mesma, mas a atitude é outra e a indumentária muda de cores e de qualidade, destacando-se a casaca branca de corte mais apurado e flor na lapela, a calça xadrez e o sapato de bico longo denotando clara intenção 
de elegância. Mais expressivos, porém, são os apetrechos que compõem a figura. O cachimbo, a bengala e o chapéu permanecem, mas deslocados para outras posições: o primeiro, ainda fumarento, repousa no chão, à frente do escritor; o chapéu, claramente mais elegante, encontra-se atrás, também no chão, mas sobre um par de luvas; a bengala, por sua vez, é exatamente a mesma, porém deixa de servir de apoio para se exibir como peça da indumentária, apertada entre o braço e o corpo. Dessa forma, as mãos, que antes se ocupam em segurar a bengala e o cachimbo, ficam agora livres para outras funções: a esquerda, em vez do cachimbo, segura desproporcionais folhas de papel que estão sendo lidas, enquanto a direita se eleva com o indicador e o polegar unidos, como a pontuar passagens da leitura. Assim como no restante da caracterização, chamam a atenção os detalhes dos dedos, com curvas insinuantes e unhas bem delineadas, que acentuam o significado do gesto. Trata-se, em suma, da figura de um escritor elegante, que não deixa de manter os traços cômicos de outras representações, como a cabeleira, os bigodes, o sapato de ponta levantada, para não falar dos elementos contrastantes que compõem o desenho, dentre os quais assume maior relevo a fumaça do cachimbo, que se eleva do chão e parece mirar o circulo formado pelos dedos unidos do escritor.

Mais uma vez, o diálogo entre o desenho de Voltolino e o texto de Alexandre Machado contribui de forma altamente eficaz para dar vida à figura do escritor Juó Bananére. Assim, mesmo sem o apoio de uma análise minuciosa dos belos traços do caricaturista, não é dificil perceber a duplicidade apontada anteriormente na caracterização do autor fictício, com as respectivas consequências paródicas.

O dado mais relevante na construção dessa figura de escritor, que a diferencia de um simples pseudônimo de Alexandre Machado, é que Juó Bananére torna-se, de fato, personagem. Nessa condição é que morava na Baixada do Piques e escrevia cartas ao Pirralho, cuja redação ficava num sobrado da rua 15 de Novembro, um dos lados do chamado Triângulo, por corresponder à região formada pelas ruas Direita, São Bento e Quinze de Novembro e considerada ponto de encontro da elite paulistana. Em suas cartas, sempre de forma bem-humorada e crítica, abordava todo e qualquer assunto e, ao mesmo tempo, dava forma a um universo ficcional povoado por uma grande variedade de personagens. Além dele próprio e da familia inventada, figuras reais eram incorporadas em seus textos, tornando-se igualmente ficcionais. É o caso, por exemplo, do Capitó (personagem baseada no político paulista Rodolfo Nogueira da Rocha Miranda), do Garonello (inspirada no coronel do Exército José Brasil Paulista Piedade), do Lacarato (referência ao delegado de polícia Antônio Nacarato) e do próprio presidente Hermes da Fonseca. No foro íntimo, Bananére possuía uma familia, constituida por mulher, filhos, genro, neto, além de uma amante (Figura 5).

Figura 5 - Desenho da familia de Juó Bananére

\section{A nuova fultogralfia th a mia vaniglia,}

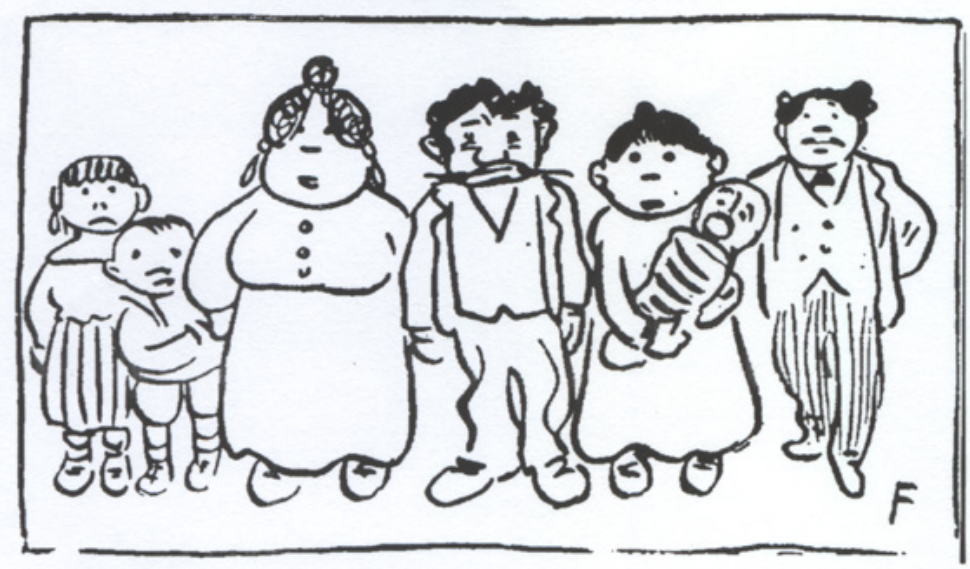

Fonte:O Pirralho, ano 2, n. 84, p. 10, 29 mar. 1913. 
A sua personagem é volúvel, múltipla e contraditória, com origem, idade e outras qualidades variando segundo as circunstâncias. Profissionalmente, é apresentado em Tristezza como "poeta, barbiére i giurnaliste" (BANANÉRE, 1924, p. 41). Essas são, por assim dizer, suas fantasias mais constantes e cômicas. Tristezza traz ainda outras referências ao seu universo ficcional, como o assassinato da mulher. Mas a preocupação de se apresentar como jornalista, poeta, escritor, perpassa vários de seus textos.

É sob essa personalidade literária que Juó Bananére escreve as cartas publicadas na coluna "As Cartas d'Abax'o Pigues" e em outras que manteve no periódico O Pirralho até meados de 1917. Esses textos eram constituídos sobretudo de paródias dos jornais, dos jornalistas, das figuras conhecidas da época, da cultura, especialmente da literatura, em que seus alvos preferidos eram os poetas românticos e parnasianos, como Gonçalves Dias, Álvares de Azevedo, Olavo Bilac, além de clássicos como Camões e outros autores universais. Confirmando o seu perfil de escritor, publicou em 1915 a primeira versão de La divina increnca, na qual reuniu algumas dessas paródias.

\section{3 escritor em ação}

A figura de escritor não teria futuro se não estivesse assentada numa linguagem original, capaz de ir além da simples crítica a representantes do beletrismo brasileiro da época, que inclusive seriam objeto de inúmeras paródias modernistas. Foi a linguagem macarrônica que deu vida e longevidade àquilo que poderia não ter passado de uma brincadeira de ocasião. Um aspecto decisivo dessa linguagem, entendida como gênero que contempla diversos níveis de mistura, é que ela cria condições inusitadas para a abordagem dos assuntos. Integrada à natureza paródica da personagem, permite, por exemplo, que Bananére participe diretamente dos acontecimentos relatados ou os observe de uma posição privilegiada, vivendo, na expressão de Alcântara Machado, "momentos de cinismo" que seriam mais saborosos do que os de indignação, uma vez que, sendo "íntimo e cúmplice de todos os poderosos da vida, vinha cinicamente confessar de público as façanhas inconfessáveis" (MACHADO, 1940, p. 256).

Outro elemento fundamental da linguagem macarrônica é que ela proporciona condições para expressar aquilo que o idioma oficial não permitia. Como destaca a nota publicada no Diário do Abax'o Piques (1933, p. 2) por ocasião da morte de Alexandre Machado, o princípio da mistura das duas línguas criava recursos reveladores ao seu estilo: "Aos olhos habituados a ver os fatos como eles são apresentados de costume - dissimulados numa tessitura de mentiras e eufemismos -, Juó Bananére mostrava-os sem disfarce, substituindo os pretextos alegados pelas causas verdadeiras". E, mais adiante, a nota completa: "Utilizando-se de um idioma exclusivamente seu, ele fugia ao perigo de ser traído pelo linguajar correto, que está viciado em contar pretextos".

Dessa forma, a linguagem macarrônica instaura um processo de expansão da mistura para praticamente todos os niveis textuais, revelando-se um recurso fundamental da personagem paródica. Dito de outro modo, a paródia constitui o recurso estilístico por excelência da linguagem macarrônica. É ela que coloca em cena o escritor Juó Bananére, como se pode acompanhar nas passagens apresentadas a seguir. Observe-se, inicialmente, o texto em que o escritor anuncia, na edição de 18 de setembro de 1915 de O Pirralho. o lançamento de seu livro La Divina Increnca.

\begin{abstract}
Tegno oggi o brutto prazere di acumunicá p'rus mignos inleitori che brevemente vó impubricá un bunito livro di verso. Sará sê duvida o maiore cuntecimento litteráro i pulittico da epoca, na pinió du Ri Barboza, do suo collega o dott. Barbigna, ecc. ecc (BANANÉRE, 1915a, p. 4).
\end{abstract}

Os níveis paródicos desse texto são representativos do macarrônico de Bananére. Embora se trate de um autor fictício, o livro será de fato publicado e contaria de antemão com o aval de respeitados intelectuais do momento, que o consideram "o maiore cuntecimento litteráro i pulittico da epoca" (BANANÉRE, 1915a, p. 4). Ao mesmo tempo em que são utilizados para colocar o evento em alto nivel, ultrapassando o campo literário e atingindo, não 
sem consequências, a esfera política, os intelectuais, são ridicularizados pela intimidade com a figura do escritor cômico, que thes deforma o nome e, portanto, o prestígio, enredando-os no processo que desloca a situação para outro universo. $\mathrm{Na}$ sequência, o texto consolida a inversão típica da paródia, dando como original a sua autoria e como plágio os poemas parodiados:

Tuttas poisias só originale mio: - "A Garibú", "O Studenti du Bó Ritiro", "Boanotte Raule" ecc. A Garibú insiste pur aí una traduçó in portoghese, fazida d'aquillo ganzonetiste frigano xamado os Gerardo. Tambê du "Studenti du Bó Ritiro" insiste una traduçó portoghese xamada o "Studenti Arsaziano", ma tuttas duas só copiado di mim; o originale só io.

[...]

P'rus inleitore non pensá chi o livrio non é gotuba, e che io stó facendo garganta, io giá vô dá una amostra. Tê por insempio una poisia xamada "Sodades" che incomincia cosí:

Tegno sodades dista Bauliçéa,

Dista cidadi chi tanto dimiro!

Tegno sodades distu çeu azur,

Das bellas figlia lá du Bó Ritiro. (BANANÉRE, 1915a, p. 4).

Depois de apresentar a primeira estrofe da paródia do poema "Versos a um viajante", de Castro Alves, diz que ainda vai "dá otra amostra, una linda poisia chi Arvaro di Zevêdo copió virgognosamente di mim" (BANANÉRE, 1915a, p. 4), e apresenta "Tritezza", paródia de "Lembrança de morrer", de Álvares de Azevedo, mencionada anteriormente.

Um mês depois, na edição de 16 de outubro de 1915, ele volta a apresentar seus "poemas", aproveitando a presença de Olavo Bilac em São Paulo. Vale recordar que seus textos mais elaborados se encontram talvez na paródia literária. E nas diversas paródias feitas por Bananére, Olavo Bilac, pela posição que ocupava, foi a principal vitima de suas investidas. ${ }^{4}$ Em 15 de outubro de 1915, o príncipe dos poetas brasileiros visitara São Paulo e tinha sido homenageado pelos intelectuais em diversos eventos. $A$ imprensa, inclusive $O$ Pirralho, não economizou palavras para registrar a sua presença na cidade. Bananére acompanha os eventos e registra sua versão no dia seguinte:

\section{A VESTA DU BILACCO}

Quartaffera tive a nunciada vesta du Bilacco, o principe dus poete brasiliéro, o Dante anazionalo. Uh! mamma mia, che successo! O saló stavo xiigno piore du garnevalo na rua 15. Os lustre di gaiz stavo xiigno di genti pindurada. Gada lustro apparicia un gáxo di banana di genti.

Bilacco dissi moltos sunetto gotuba. Impubricamos imbaxo uno insemplare.

\section{UVI STRELLA}

Che scuitá strella né meia strella!

Vucê stá maluco! e io ti diró intanto,

Chi p'ra scuitalas moltas veiz livanto,

I vô dá una spiada na gianella.

I passo as notte acunversáno c'oella, Inquanto chi as otra lá d'un ganto Stó mi spiáno. I o sol come un briglianto Naçe. Óglio p'ru çeu: Cadê strella!?

Direis intó: Ó migno inlustro amigo!

O chi é chi as strella ti dizia

Quano illas viéro acunversá contigo?

E io ti diró: Studi p'ra intendel-a,

Pois só chi giá studô Astrolomia,

É capaiz di intendê istas strella (BANANÉRE, 1915b, p. 4)

Aqui, a paródia de "Via láctea" é apresentada gaiatamente como transcrição do poema declamado por Bilac, em que a deformação é decorrente da própria condição do "giurnaliste". O elemento cômico é evidente em todo o texto, seja por causa do próprio estilo macarrônico, que inverte o sentido das palavras, seja pelo desfecho, que quebra a expectativa do leitor ao substituir a atitude sublime de contemplar as estrelas no poema original pelo exame objetivo do estudioso na sua paródia. O ataque mais contundente a Bilac viria, porém, na edição seguinte do periódico. Bananére publica em sua coluna uma deliciosa, mas por isso mesmo ferina, paródia de seu famoso discurso pronunciado em 9 de outubro

\footnotetext{
4 Cabe recordar que a irreverência de Bananére, embora tivesse como alvo privilegiado a poesia parnasiana, não deixou de atacar também as propostas de vanguarda, em particular a poesia futurista, fazendo paródias da vanguarda de Marinetti muito antes de sua ampla divulgação no País (ANTUNES, 2003).
} 
de 1915, na Faculdade de Direito de São Paulo, num texto intitulado "O nazionalizimo". 5 Este texto chega a causar problemas a Alexandre Machado n'O Pirralho, pois a direção do periódico não concorda com a dessacralização do ícone literário e político. O festejado Bilac era um símbolo nacional, que defendia ideias patrióticas, como o serviço militar obrigatório e o culto da língua nacional. Seguindo a imprensa, que dá grande destaque à visita, Bananére cria a sua versão de homem de letras com prestígio social. O texto é contundente, primeiramente, porque atinge traços evidentes tanto da figura de Bilac como de seu estilo pomposo. Depois, porque, como macarrônico, abre várias perspectivas críticas no plano literário, social e político.

O escritor começa apresentando as suas credenciais para ser convidado pelos estudantes da Gademia di Cumerço du Braiz:

Non é só o Bilacco che é uomo de lettera - io també! lo també scrivo verso, io també scrivo Livro di poisies chi o Xiquigno vai inditá i chi vuceis vô vê si non é migliore dus livro du Bilacco! Intó, pur causa che io só un úomo di lettera gotuba, os studenti da Gademia di Cumerço du Braiz mi furo acunvidá ista settimana p'a í avisitá a rifirita Gademia

(BANANÉRE, 1915C, p. 12).

Depois de relatar o deslocamento da Praça da Sé ao Brás, acompanhado de estudantes que lotaram dois bondes especiais, trata de sua recepção pelo povaréu, com banda de música e tudo, e pelo "gorpo indecente da Gademia" que o conduziu ao salão nobre onde faz seu discurso:

"Signori!

lo stó intirigno impegnorato con ista magninifica recepiçó chi vuceis acaba di afazê inzima di mim. É molta onra p'run pobri marqueiz! (Tuttos munno grita: nó apuiado! nó apuiado!) lo ê di si ricordá internamente, i con molta ingratidó distu die di oggi! I aóra mi permittano che io parli un pocco da golonia intaliana in Zan Baolo, istu pidaço du goraçó da Intalia, atirado porca sorte inzima distas pragana merigana. É una golonia ingollossale! maise di mezzo millió de intaliano stó ajugado aqui, du Braiz ô Bó Ritiro. i du Billezigno ô Bixigue! I chi faiz istu mundo di intaliano chi non toma gonta du cumerçu, das fabbrica, da pulittica, du guvernimo, i non botta u Duche dus Abruzzo come prisidenti du Stá nu lugáro du Rodrigo Alveros?

Sabi o que faiz? Vendi banana, fragora, ova frisca, sorbeta de grema i vigno infarsifigato! Faiz o infabricanti di nota farsa inveiz di afazé o fabricanti di argodó p'ra baratiá o produttimo! Faiz o ladró di galligna inveiz di griá vacca p'ra vendê garne di vacca p'ra Ingraterra. Anda gatáno paper sugio i tocco di sigarro na rua inveiz di catá ôro nu sertó como un bandeiranti! I quali é a cunsequenza disto relaxamento? É chi os intaliano aqui non manda nada, quano puteva inveiz aguverná ista porcheria!

Quale é a consequenza da bidicaçó da nostra forza i du nostro nazionalisimo?

É chi nasce una grianza, a máia é intaliana, o páio é intaliano e illo nasce é un gara di braziliano!

Istu non podi ingontinuá, no! A voiz chi sono giovani i forte cumpette afazé a reacçó, cumbatté, vencê i dinominá istu tudo! Tegno ditto" (BANANÉRE, 1915C, p. 12).

Segundo o seu relato cômico, após o discurso, "rompê una brutta sarva di parma" e ele é carregado até o bonde elétrico. Esse texto faz par com as paródias poéticas, e nele é possivel perceber uma gama variada de inversões, principalmente a do nacionalismo aplicado não aos brasileiros, mas aos italianos residentes no Brasil, desmontando sarcasticamente o patriotismo de Bilac, que em seu discurso na Faculdade de Direito havia feito referência à imigração como desagregadora da nação brasileira:

Que tem feito, que se está fazendo para a definitiva constituição da nossa nacionalidade? Nada.

Os imigrantes europeus mantêm aqui a sua lingua e os seus costumes. Outros idiomas e outras tradições deitam raizes, fixam-se na terra, viçam, prosperam. E a nossa lingua fenece, o nosso passado apaga-se... (BILAC, 1915, p. 9).

A desmontagem utiliza, inicialmente, a imitação da retórica de Bilac, ao qual Bananére se compara dizendo que também escreve livros de poesias, o que the confere um caráter de autoridade que faz jus ao convite dos estudantes da Academia de Comércio do Brás. O tom rebaixado da comparação entre ele e Olavo Bilac, entretanto, manifesta-se em todos os niveis do texto, da linguagem às condições gerais da recepção que lhe fazem

5 Nos comentários deste texto, retomo parcialmente análise apresentada em ANTUNES (1998). 
os estudantes, estabelecendo-se sempre uma tensão entre uma e outra, de modo a desnudar a impostação afetada do objeto parodiado.

Observa-se, por exemplo, que Bananére explicita o tom folgado da comitiva que acompanha o conferencista do Largo da Sé à Academia, numa espécie de marche au flambleau às avessas: "Intó, fumos tuttos giunto, afazéno una brutta sgugliambaçó nu gamigno; quano apassemos na scuola Normale tuttas moça mi ajuga begigno p'ra mi. Uh! che gustoso!" (BANANÉRE, 1915c, p. 12). Além de fazer troça com a falsa modéstia característica em tais circunstâncias, o narrador compraz-se com a exagerada manifestação de que é alvo: "Uh! che gustoso!". Da mesma forma, não usa de falsos moralismos ao se referir às atividades dos italianos em São Paulo, que incluem a fabricação de vinho e dinheiro falsos e outras atividades pouco nobres, como roubar galinhas e catar toco de cigarro na rua. Note-se ainda que ele é recebido na Academia pelo "gorpo indecente" e demonstra "molta ingratidó" pela acolhida. Ou seja, as inversões dos aspectos aparentemente sérios de um cerimonial dessa natureza vão revelando, no texto macarrônico, tudo o que há de empolado e artificial no acontecimento parodiado, culminando na exortação militarista dirigida ao jovem "intaliano", que no discurso de Bilac vinha disfarçada em sentimento nacionalista: "A voiz chi sono giovani i forte cumpette afazé a reacçó, cumbatté, vencê i dinominá istu tudo!" Vale notar, neste ponto, que o uso do prefixo "in" na palavra "intaliano", além de representar a prosódia do imigrante, sugere, no âmbito do estilo macarrônico, a própria ambiguidade da situação do imigrante, que faz dele um deslocado espacial e culturalmente, um "não italiano".

A rigor, a paródia aplica-se mais aos aduladores de Bilac do que a ele próprio. Basta ler os discursos de saudação com que o poeta foi recebido em São Paulo naquele momento para se entender o alvo. O Estado de S. Paulo, por exemplo, adota tom emocional para noticiar a visita que o poeta faz à Academia de Direito, dizendo que ele é "recebido pelos estudantes debaixo das mais entusiásticas aclamações". Em seguida, informa que sua presença no "velho casarão do Largo de São Francisco" "alvoroçou o coração da mocidade". Por fim, saúda o homenageado como o "cantor másculo, o vigoroso cantor patriótico e inspirado das nossas epopeias, das nossas tradições nacionais, da beleza exuberante da nossa terra virgem e ignorada..." (OLAVO...,1915, p. 5).

Esse linguajar não é adotado somente pela grande imprensa. O Pirralho, na cobertura do evento, fugindo um pouco de seu tom humorístico, repete inúmeras vezes a palavra entusiasmo para expressar o sentimento da juventude que se acotovelou na Faculdade de Direito para ouvir Bilac. Em vários momentos, chega a exagerar: "Na Academia de Direito pronunciou um discurso que ficará na nossa história. Nas Escolas, na intimidade dos grupos que o procuram, nas visitas que faz, Bilac espalha e derrama consolação, fé, entusiasmo, alegria" (BILAC..., 1915, p. 8). No texto "A festa de Bilac", não poupa adjetivos: "Bilac está em São Paulo. E São Paulo se acende de festas, de entusiasmo, de apoteoses. [...] A fase atual de Bilac é uma gloriosa fase que faria a reputação de qualquer literatura. / Salve, cantor estupendo!" (A FESTA..., 1915, p. 10).

Nesse clima de entusiasmo, é fácil perceber o peso da paródia de Bananére. É preciso recordar que a imprensa, incluindo O Pirralho, encampou a campanha cívica da qual Bilac passou a ser o principal representante. E Bananére toma partido oposto. Mais importantes, porém, são os desdobramentos proporcionados pela linguagem macarrônica. Além da crítica ácida ao ambiente acadêmico e literário, ela atinge aspectos sociais e políticos relevantes naquele momento, como as questões relacionadas à integração do imigrante à sociedade brasileira, colocada a nu pelo desmonte do discurso nacionalista.

\section{Considerações finais}

A partir da mistura inicial de duas linguas, Juó Bananére logra criar uma linguagem em que outras misturas ficam autorizadas. O recurso deixa o narrador à vontade para romper as barreiras entre ficção e realidade, bem como as dimensões de espaço e de tempo, tomando com isso rumos 
inusitados. Permite fundamentalmente estabelecer uma perspectiva crítica mais aprofundada graças à independência com que transita por códigos e temas. No caso do imigrante italiano, por exemplo, logra distanciar-se da simples tentativa de representação e atinge niveis mais complexos do problema. Além disso, a máscara do imigrante, graças ao seu componente cômico, que incorpora de modo deslocado um dado cultural de todos conhecido, traz em si uma perspectiva que the permite enfrentar questões culturais, sociais e politicas numa dinâmica que vai além do esquema oficial e estreito.

Entre as várias possibilidades de sentido, os textos de Bananére parecem sugerir a expressão atualizada do processo de formação da cultura brasileira, entendida como transplante da cultura europeia para o Brasil. Esse processo inicia-se no século XVI, com as primeiras ações da conquista, e passa por momentos mais ou menos acentuados, em conformidade com o sentimento nativista, primeiro, e nacionalista, depois. Essa tentativa levou Sérgio Buarque de Holanda a considerar os brasileiros "desterrados" em sua própria terra: "Trazendo de países distantes nossa forma de convívio, nossas instituições, nossas ideias, e timbrando em manter tudo isso em ambiente muitas vezes desfavorável e hostil, somos ainda hoje uns desterrados em nossa terra" (2006, p. 19).

Com efeito, a consciência nacionalista encobre muitas vezes uma procura de identidade própria. Num país de cultura imposta como a brasileira, a tensão entre a matriz e a colônia, com as transformações do legado importado, acaba gerando produtos nem sempre puros, mas frutos de cruzamentos, miscigenação, apropriações e misturas várias. Nesse sentido, uma linguagem como o macarrônico, cujo princípio constitutivo é a aproximação constante de elementos impróprios, parece expressar em nivel profundo elementos estruturais da formação e da própria maneira de ser do brasileiro.

Com isto, Bananére revela plena consciência do deslocamento de certas ideias e comportamentos brasileiros, principalmente em São Paulo, que passava no início do século XX por um processo abrupto de urbanização. A imigração iniciada no século anterior aumenta e chega a ser estimulada para atender à necessidade de mão de obra. Outra parte se desloca das fazendas de café para a Capital. A cidade cresce de modo rápido e pouco planejado. Paralelamente, intensifica-se o contato com a cultura europeia por meio de produtos de consumo, espetáculos teatrais, moda e hábitos. Enquanto no plano mais sofisticado prevalece a influência francesa, no setor operário é o imigrante italiano que ocupa a maioria dos espaços, disseminando gostos e hábitos. Este aspecto está sem dúvida entre as razões do sucesso de uma criação como o macarrônico ítalo-brasileiro. A permanência do sucesso, mais de cem anos depois, indica que o estilo captou algo mais profundo e menos circunstancial do fenômeno. É possivel, assim, que o estilo de Bananére e aquilo que ele representa ainda hoje tenham a ver com a condição do Brasil como país construido pelo transplante da cultura europeia. Nesse sentido, explorando o recurso das inversões que a paródia autoriza, até lhe caberia o epíteto de "cantor másculo, o vigoroso cantor patriótico e inspirado das nossas epopeias" atribuído na época pelo jornal O Estado de S. Paulo a Bilac.

\section{Referências}

A FESTA de Bilac. O Pirralho, São Paulo, ano 5, n. 204. p. 10,16 out. 1915 .

ANTUNES, Benedito. A lingua macarrônica n'O Pirralho e a vanguarda modernista. In: WATAGHIN, Lucia (org.). Brasil/Itália: vanguardas. São Paulo: Ateliê, 2003. p. 239-51.

ANTUNES, Benedito. O imigrante italiano na literatura paulista. In: CAPRARA, Loredana de Stauber; ANTUNES, Letizia Zini (org.). O italiano falado e escrito. São Paulo: Humanitas; FFLCH/USP, 1998. p. 199-214.

BANANÉRE, Juó. As cartas d'abax'o o Piques. O Pirralho São Paulo, ano 5, n. 202, p. 4, 18 set. 1915a.

BANANÉRE, Juó. A vesta du Bilacco. O Pirralho, São Paulo, ano 5, n. 204, 16 out. 1915b. As cartas d'abax'o o Piques. p. 4.

BANANÉRE, Juó. La divina increnca. São Paulo: Livraria do Globo, Irmãos Marrano Editores, 1924.

BANANÉRE, Juó. O nazionalizimo. O Pirralho, São Paulo, ano 5, n. 205, 30 out. 1915C. As cartas d'abax'o o Piques. p. 12. 
BELLUZZO, Ana Maria. Voltolino e as raizes do Modernismo. São Paulo: Marco Zero, Programa Nacional do Centenário da República e Bicentenário da Inconfidência Mineira, MCT/CNPq. Secretaria de Estado da Cultura de São Paulo, 1992.

BILAC em São Paulo. O Pirralho, São Paulo, ano 5, n. 204, p. 8-10, 16 out. 1915

BOSI, Alfredo. O Pré-Modernismo. 3. ed. São Paulo: Cultrix, 1969. (A literatura brasileira, 5).

CANDIDO, Antonio. Literatura e cultura de 1900 a 1945. In: CANDIDO, Antonio. Literatura e sociedade. São Paulo: Companhia Editora Nacional, 1973. p. 109-138.

CAPELA, Carlos Eduardo S. Juó Bananére: irrisor, irrisório. São Paulo: Nankin; Edusp, 2009.

CARMO, Maurício Martins do Carmo. Paulicéia scugliambada, Paulicéia desvairada: Juó Bananére e a imagem do italiano na literatura brasileira. Niterói: EDUFF, 1997.

DERTÔNIO, Hilário O bairro do Bom Retiro: apelidos e tipos. São Paulo: Secretaria Municipal de Cultura, 1975.

ESTE número 17. Diário do Abax'o Piques, São Paulo, ano 1, n. 17, p. 1, 30 set. 1933

FONSECA, Cristina. Juó Bananére: o abuso da blague. São Paulo: Editora 34, 2001.

HOLANDA, Sérgio Buarque de. Raizes do Brasil. São Paulo: Companhia das Letras, 2006.

MACHADO, Antônio de Alcântara. Cavaquinho e saxofone. Rio de Janeiro: José Olympio, 1940.

OLAVO Bilac: A sua visita à Academia. O Estado de S. Paulo, São Paulo, ano 41, n. 13440, p. 5, 10 out. 1915

O PIRRALHO. São Paulo. 12 ago. 1911-23 fev. 1918.

PAES, José Paulo. O art nouveau na literatura brasileira. In: PAES, José Paulo. Gregos e baianos: ensaios. São Paulo: Brasiliense, 1985. p. 64-80.

\section{Benedito Antunes}

Doutor em Letras pela Universidade Estadual Paulista (UNESP), em Assis, SP, Brasil, professor da Universidade Estadual Paulista (UNESP), em Assis, SP, Brasil; e bolsista de produtividade em pesquisa do Conselho Nacional de Desenvolvimento Científico e Tecnológico (CNPq).

\section{Endereço para correspondência}

Benedito Antunes

Universidade Estadual Paulista

Faculdade de Ciências e Letras/ Campus de Assis

Av. Dom Antônio, 2100

Parque Universitário, 19806-900

Assis, SP, Brasil 